\title{
Effect of Extraction Methods and Wheat Cultivars on Gluten Functionality
}

\author{
Snehil Dua, Odean M. Lukow*, Gavin Humphreys and Kathy Adams
}

Agriculture and Agri-Food Canada, Cereal Research Centre, 195 Dafoe Road, Winnipeg, MB, R3T 2M9, Canada

\begin{abstract}
The functionality of gluten extracted from Canada Western Red Spring (CWRS) and Canada Western Extra Strong (CWES) wheat flours was evaluated and compared. The extra-strong wheat cultivars had stronger dough properties and produced smaller bread loaves than AC Barrie. Modifications of a starch displacement gluten extraction method were evaluated. For optimal gluten formation and extraction, water to flour ratio of $0.87 \%$ and dough mixing to $30 \%$ after peak dough development were used. Water and cold ethanol were compared for their effectiveness in gluten extraction by evaluating gluten yield and functionality in a soft wheat flour blend. The ethanol method produced higher yields of gluten, but these gluten extracts had significantly lower protein contents than the respective glutens extracted with water. Farinograph analyses of soft wheat flour fortified with gluten extracts to $14.5 \%$ protein content showed significant differences in dough development time, stability and mixing tolerance index between water- and ethanol-extracted gluten extracts; glutens extracted with ethanol had significantly stronger dough properties and also had higher 50PI:50PS gluten ratios. Whereas ethanol-extracted gluten decreased or had no effect on loaf volume, water-extracted gluten improved bread loaf volumes when added to soft wheat flour. The inherent differences in quality between CWRS and CWES flour was reflected in the gluten extracted by water, but not in the gluten extracted by ethanol.
\end{abstract}

Keywords: Wheat gluten, water extraction, ethanol extraction, wheat quality.

\section{INTRODUCTION}

Wheat gluten is marketed commercially in two forms, 'non-vital' and 'vital' [1]. Non-vital wheat gluten is the gluten that has undergone irreversible denaturation and cannot be revitalized. It absorbs water in an amount related to its particle size and distribution. In contrast, vital dry gluten in contact with water re-hydrates rapidly and regains its intrinsic functionality. The functionality of gluten is very important for improving baking performance and may be affected by several factors at different stages of gluten extraction. Vitality of gluten has been related to the rate of water absorption and the degree of viscoelasticity [1].

Extraction of gluten has been carried out by various methods that involve formation of dough/batter from wheat flour followed by separation of gluten from the remaining components either by washing [2-8] or by ultracentrifugation [9]. Commercially gluten is prepared by washing the wheat dough with water according to the over 150 year old Martin process. The Martin process involves mixing of wheat flour to form a dough with about $60 \%$ of its weight with water, separating starch from gluten by washing the dough with water and finally drying of the extracted gluten [2]. A modification of the Martin process is the batter method, in which a batter or slack dough is formed from wheat flour with 70$110 \%$ water [10]. The batter or slack dough is dispersed in large quantities of water and passed through a set of sieves to separate starch and water soluble components from the gluten matrix [2]. The wet gluten is then air dried at high temperatures. This method has also been modified at various stages $[3-8,10,11]$.

*Address correspondence to this author at the Agriculture and Agri-Food Canada, Cereal Research Centre, 195 Dafoe Road, Winnipeg, MB, R3T 2M9, Canada; Tel: (204) 983-1629; Fax: (204) 983-4604;

E-mail: Odean.Lukow@agr.gc.ca
At the stage of mixing the flour with water, the proportion of water: flour while dough/batter formation takes place, has been shown to significantly influence the functionality of the extracted gluten [10-12]. In a response surface study on gluten extraction from low-grade flour and durum flour, it was found that the protein concentration in protein fraction increased as the water content in the dough increased from $400 \mathrm{gKg}^{-1}$ to $710 \mathrm{~g} \mathrm{Kg}^{-1}$ [11]. Gluten agglomeration increased with increasing water content in the batter method $[10,13$, 14].

Frederix et al. [10] reported that gluten agglomeration improved with increasing the dough mixing time (2 to $6 \mathrm{~min}$ ) and suggested that this was due to better dough development with longer mixing times. Different wheat classes have been used for gluten extraction and a wide range of mixing times for dough/batter formation have been reported that can be related to the genetic background of the wheat $[15,16,17]$. Thus, it may be possible to base the dough mixing time for gluten extraction on the dough mixing curves as opposed to a fixed time for all the wheat classes.

Cold ethanol has been tested for displacing the starch from the developed dough $[3,4]$. Although water is used on a commercial scale for the displacement of starch from gluten because of its ease of use and availability, the functionality of the resulting gluten is often inferior to native gluten [3, 4]. It has been suggested that cold ethanol is a better solvent for starch displacement [4-7]. When cold ethanol was used to displace starch from the gluten matrix, there was a significant advantage of ethanol compared to water in terms of gluten functionality. Dilutions of $0-100 \%$ aqueous ethanol at a range of temperatures were tested [18]. Ethanol was most effective and economical as an extractant of gluten at $70 \%$ concentration and $-13^{\circ} \mathrm{C}$ [18]. The functionality of gluten 
could be improved by replacing the starch displacement fluid from water to $70 \%$ ethanol [3-6].

The final step of gluten extraction is the drying of the gluten extract. Drying of the gluten extract has received considerable attention by the researchers because high temperature drying often has deleterious effects on the gluten functionality [19]. For commercial gluten production, the gluten is dried with high temperature air, whereas in the laboratory, freezing and vacuum drying have been reported to produce gluten with better functionality for breadmaking [1, 17].

To determine the differences in the functionality of gluten extracts, quality parameters like mixograph and farinograph parameters and bread loaf volume may be very useful. Several researchers [4-6, 17, 20] have reported the use of the mixograph, farinograph and extensigraph for testing the functionality of vital gluten prepared by different treatments. In addition, the ability of gluten extracts to improve breadmaking performance, that is, loaf volume and crumb structure, of weaker flours is a standard assessment procedure [21].

The goals of this study were to optimize the gluten extraction procedure for gluten functionality and to determine if extra-strong mixing wheat can prove to be a better choice for gluten source than strong mixing wheat. The specific objectives of the study were, 1) to determine the optimum water: flour ratio and time for mixing the dough for gluten extraction, 2) to compare the effects of water at $10^{\circ} \mathrm{C}$ and ethanol at $-10^{\circ} \mathrm{C}$ for displacement of starch for gluten extraction on the functionality and yield of the extracted gluten and, 3) to determine the differences in functionality between the gluten extracts obtained from Canada Western Red Spring (CWRS) and Canada Western Extra Strong (CWES) wheat flours.

\section{MATERIALS AND METHODS}

\section{Material}

In a preliminary study, composite CWRS and composite CWES wheat samples were used to determine optimum water content and dough mixing time for gluten extraction. The addition of $10 \%$ powdered gluten of CWRS and CWES composites to AC Meena flour $(10.1 \%$ protein content, $14.0 \%$ moisture basis $(\mathrm{mb})$ ) was used to determine the functionality of the gluten extracts.

For the comparison of gluten extractions from CWRS and CWES wheat classes, three CWES (Glenlea, AC Corrine and CDC Rama) and one CWRS (AC Barrie) wheat cultivars grown in Portage la Prairie, Manitoba in 2006 were used. The CWRS class is known for its hard wheat with superior milling and baking quality; the CWES class consists of hard wheat with extra-strong dough properties that are suitable for blending purposes [15]. The grain was milled into straightgrade flour using a Buhler experimental mill (Buhler AG, Uzwil, Switzerland) after tempering to $16.5 \% \mathrm{mb}$. Powdered gluten of individual cultivars was added to the composite soft wheat flour $(11.0 \%$ protein content, $14.0 \% \mathrm{mb})$ for quality analyses, such that the flour/gluten blends had $14.5 \pm$ $0.1 \%$ protein content on a $14 \% \mathrm{mb}$.

\section{Physicochemical Tests}

Protein and moisture content of the flours and flour/gluten blends were determined using a Dickey-John
Instalab 600 near-infrared (NIR) analyzer (Dickey-John Corporation, Cornwall, ON). Gluten protein content ( $\mathrm{N} x$ 5.7) was determined by the combustion nitrogen analysis method (method 46-30) [22] using a Leco FP-528 nitrogen analyser (Leco Inc, St Joseph, MI). Moisture contents (method 44-15A) [22] of the gluten fractions were also determined. Sedimentation volume and gluten index (methods 56-11 and 38-12A) [22] of the wholemeal were measured. The color of gluten extracts was measured in CIE color coordinates $\left(\mathrm{L}^{*} \mathrm{a}^{*} \mathrm{~b}^{*}\right)$ with a Minolta spectrophotometer (Model CM- 525i, Minolta, Osaka, Japan) set at $2^{\circ}$ observer and "C" illuminant. The $\mathrm{L}^{*}, \mathrm{a}^{*}$ and $\mathrm{b}^{*}$ color coordinates measure the degree of brightness/lightness ( $\left.\mathrm{L}^{*}\right)$, redness $\left(\mathrm{a}^{*}\right)$ and yellowness $\left(b^{*}\right)$ of a sample. The 50PI:50PS ratio was measured for wholemeal samples of AC Barrie, Glenlea, AC Corrine and CDC Rama and the soft wheat flour blended with gluten extracts to $14.5 \%$ protein content, following the method of Suchy et al. [23].

\section{Gluten Extraction Procedure}

For optimization of gluten extraction, variations in mixing time (peak dough development to $70 \%$ past peak dough development) and water: flour ratio (0.66 to $1.00 \mathrm{w} / \mathrm{w})$ on a constant flour basis $(150 \mathrm{~g})$, were evaluated. A modification of the Robertson and Cao method for gluten extraction [4] was used and involved mixing the flour sample with distilled water in a GRL (Grain Research Laboratory) 200 Mixer (Muzeen and Blythe Ltd, MB, Canada) at 240rpm to form a batter. The dough was rested at $10^{\circ} \mathrm{C}$ for $1 \mathrm{~h}$, and the batter mixed twice for $5 \mathrm{~min}$ with $600 \mathrm{ml}$ distilled water $\left(10^{\circ} \mathrm{C}\right)$ and a third time for $5 \mathrm{~min}$ with $400 \mathrm{ml}$ distilled water. The batter was sieved through two sieves, $307 \mu \mathrm{m}$ (sieve 1) and $180 \mu \mathrm{m}$ (sieve 2). The glutens retained by the sieves were collected and weighed for the determination of wet gluten yield. Glutens were frozen overnight and then freeze-dried for $48 \mathrm{~h}$. The dried gluten extracts were broken into smaller pieces with mortar and pestle and then ground in a Retch Mill to $0.35 \mu \mathrm{m}$. Gluten samples were stored in plastic bags at $-5^{\circ} \mathrm{C}$ until their use in the flour blend studies.

Gluten was extracted from AC Barrie, Glenlea, AC Corrine, and CDC Rama flours using either water or ethanol as the starch displacement fluids. For water displacement of starch, dough was produced in a GRL mixer at $10^{\circ} \mathrm{C}$ using the optimum flour/water ratio and development time established in the preliminary trials. The ethanol displacement method was similar to the water displacement method, except that the procedure was carried out at $-10^{\circ} \mathrm{C}$, dough was mixed twice with $70 \%$ ethanol and finally with $95 \%$ ethanol.

\section{Dough and Gluten Rheology}

Water absorption and dough strength of the flours were determined using a 50g farinograph (method 54-12) [22] and a $10 \mathrm{~g}$ mixograph [24] at $65 \%$ absorption [25]. The farinograph measures and records resistance of dough to mixing. It is used routinely in the baking industry to determine flour absorption and to determine the rheological properties of dough during mixing. The mixograph also measures and records resistance of dough to mixing but, unlike the farinograph, is often used with small flour samples and to study the effects of added ingredients on mixing properties.

The blends of soft wheat flour and gluten extracts were evaluated for dough properties with the $10 \mathrm{~g}$ farinograph and 
the 2g mixograph (National Mfg., TMCO, Lincoln, NE) at $\mathrm{FAB}+3 \%$ [26]. The dough extensibility of flour/gluten blends were determined by a microextensibility test [27] with a $2 \mathrm{~g}$ mixograph and a TA.XT2i Texture Analyzer (Texture Technologies Corp., Scarsdale, NY/Stable Micro Systems, Goldalming, Surrey, UK).

\section{Baking Performance}

Breads were prepared using a modified longfermentation baking test (method 10-10) [22] using 70g flour, water content calculated from farinograph absorption and a proof height of $80 \mathrm{~mm}$. Loaf volume was measured by the rapeseed displacement method. Crumb firmness was evaluated by a compression testing procedure on two stacked bread slices using the TA.XT2i Texture Analyser fitted with a 7/16 inch diameter acrylic probe with bevelled edges (Texture Technologies Corp., Scarsdale, NY/Stable Micro Systems, Goldalming, Surrey, UK) and reported as force (g) at $25 \%$ compression (AIB standard method 2008) [28].

\section{Statistical Analysis}

All quality analyses were performed in duplicate. The statistical analyses were performed with SAS software (version 9.1.3, SAS Institute, Inc., Cary, NC) using the PROC GLM Model. Tukey's least square difference procedure was used to compare the means. Results presented are the means of multiple analyses of duplicate determinations on the same sample, except as otherwise indicated.

\section{RESULTS AND DISCUSSION}

\section{Optimization of Extraction Procedure}

A preliminary study was aimed at maximizing the proportion of water that can be added to the flour while achieving dough development for gluten extraction. While dough development is critical for separation of gluten from the starch, higher proportions of water result in less mechanical damage of the gluten [10]. Dough were prepared from the composite CWRS and CWES flours with varying proportions of water to flour $(0.66,0.73,0.80,0.87,0.90$ and 1.00 $\mathrm{w} / \mathrm{w})$ on a constant flour basis $(150 \mathrm{~g})$. The water to flour ratio was maximized to reduce the mechanical damage to the gluten and the optimum level was determined by repeated trials. Doughs/batters prepared at 0.66, 0.73, 0.80, 0.87 and 0.90 water to flour ratios resulted in dough formation, however, there was no dough formation at 1.00 water to flour ratio. Although it was possible to extract gluten at 0.90 water to flour ratio, the yield of gluten extract at this level was considerably lower than when the amount of extracting water was lower (ratios of $0.87,0.80,0.73$ and 0.66 ), as indicated in Table 1. The gluten yield increased appreciably by reducing the water: flour ratio to 0.87 . Further reducing the amount of water (ratios of $0.80,0.73$ and 0.66 ) did not increase the gluten yield in appreciable amounts. The water to flour ratio of $0.87(130: 150 \mathrm{w} / \mathrm{w})$ was considered optimal at the given conditions of mixing speed and temperature of the dough. These results are in agreement with other studies [10, $14,18]$ where increasing the water proportion in the formation of dough resulted in increased gluten yield when the dough was mixed for 4 or $6 \mathrm{~min}$. Robertson and co-workers $[14,18]$ used water-to-flour ratios of $0.6-1.1$ and cold ethanol to wash the batter and found that the separation of the flour in gluten and starch was improved with increased water to flour. Anderson et al. [29], on the contrary, used relatively high (1.0-1.8) water to flour proportions resulting in lower gluten recoveries, which is consistent with our results.

Table 1. Water: Flour Ratios for Gluten Development

\begin{tabular}{|c|c|c|}
\hline Flour sample & Water/flour ratio & ${\text { Wet gluten yield }\left(\mathbf{g}^{\mathbf{*}}\right.}^{\mathbf{*}}$ \\
\hline \hline Composite CWRS & 0.66 & 120.5 \\
\cline { 2 - 3 } & 0.73 & 120.2 \\
\cline { 2 - 3 } & 0.80 & 118.5 \\
\cline { 2 - 3 } & 0.87 & 113.8 \\
\cline { 2 - 3 } & 0.90 & 70.3 \\
\cline { 2 - 3 } & 1.00 & $-^{\dagger}$ \\
\hline Composite CWES & 0.66 & 105.4 \\
\cline { 2 - 3 } & 0.73 & 101.8 \\
\cline { 2 - 3 } & 0.80 & 98.2 \\
\cline { 2 - 3 } & 0.87 & 93.5 \\
\cline { 2 - 3 } & 0.90 & 50.8 \\
\cline { 2 - 3 } & 1.00 & $-^{\dagger}$ \\
\hline
\end{tabular}

Based on $150 \mathrm{~g}$ flour.

${ }^{\dagger}$ No gluten development.

To evaluate whether the yield and functionality of extracted gluten would be affected by the extent of mixing of the dough and consequent development of the gluten, different mixing levels (mixed to peak development, and 30\%, $50 \%$ and $70 \%$ after peak development) for the composite CWRS and composite CWES flour doughs mixed in a GRL mixer were tested (Fig. 1). Based on the yields and gluten strength of the extracts at different mixing levels, 30\% breakdown after peak was considered optimum mixing time for gluten extraction (Table 2). The farinograph water absorption (FAB), dough development time (DDT), stability (STA) were higher and mixing tolerance index (MTI) lower for the gluten extracted at $30 \%$ after peak development for both composite CWRS and composite CWES compared to other mixing times indicating greater functionality. Although the gluten yield was the highest for the samples that were mixed to peak dough development (Table 2) and the gluten yield decreased as the mixing time was increased, gluten functionality increased at $30 \%$ past peak dough development. Prolonged mixing of the doughs might have resulted in breakdown of the gluten network; thus, the gluten extracts were less functional when extracted from over-mixed doughs (50\% and $70 \%$ past peak). It was also possible that with prolonged mixing, some of the proteins were also released from the gluten network, as indicated by the increased amount of gluten in the second sieve (Table 2). The farinographs of the flours fortified with these glutens also indicate such damage to the gluten network. As the mixing time increased from $30 \%$ past peak development to $70 \%$ past peak development, the dough development time, and stability decreased consistently (Table 2) indicating the weakening of the gluten. Frederix et al. [10] reported increased gluten agglomeration when mixing time was increased from 2 to $6 \mathrm{~min}$. Others [14, 18] also found that the gluten-starch separation improved 
when flour and water were initially mixed longer (from 0.5 to $25 \mathrm{~min}$ ). However, mixing times exceeding $25 \mathrm{~min}$ negatively influenced the separation because of an increased mechanical degradation of the gluten matrix.

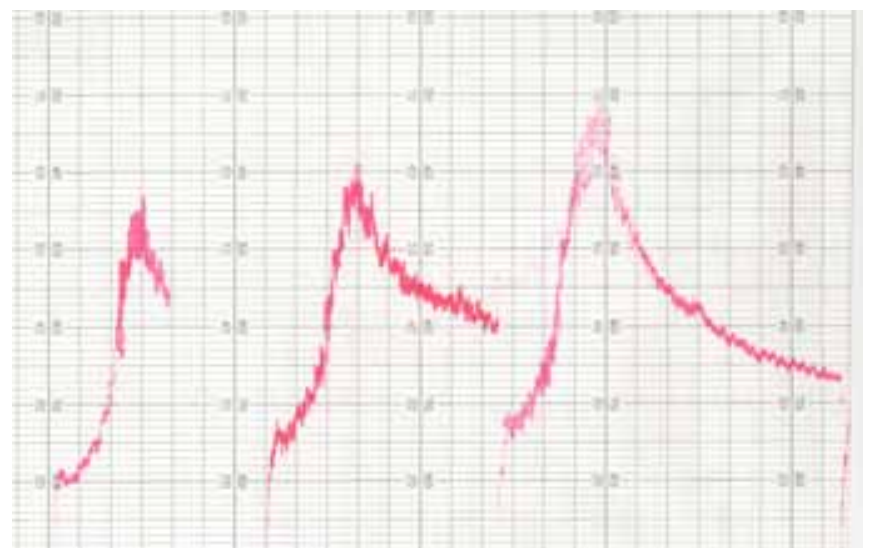

Fig. (1). Chart showing mixing curves at $30 \%, 50 \%$ and $70 \%$ after peak dough development of CWRS composite flour.

\section{Comparison of Wheat Cultivars}

The quality characteristics of the CWES and CWRS flours are given in Table 3. CDC Rama had the highest protein content. All CWES wheats (Glenlea, AC Corrine, and CDC Rama) had gluten index values significantly higher than the CWRS cultivar, AC Barrie, indicating their greater inherent gluten strength. The sedimentation volume (Table 3) showed significantly lower values for CWES flour than for the CWRS flour; the extra-strong gluten properties of CWES wheats typically reduce sedimentation volumes. All samples had high falling number values indicative of sound samples with low levels of alpha-amylase (data not shown). The mixograph development time (MDT) was significantly higher in CWES flours than in the CWRS flour. The energy to peak (ETP) was significantly higher for two CWES flours
(Glenlea and CDC Rama) confirming their stronger dough properties (Table 3). The differences in the dough strength parameters between CWRS and CWES wheats were also seen in the farinograph characteristics (Table 3). The CWES wheats had significantly higher dough development time, stability and time to breakdown compared to CWRS wheats indicating stronger dough characteristics. Determinations of the relative amounts of 50\% propanol-insoluble (50PI) to propanol-soluble (50PS) gluten components have been used to evaluate the potential of dough strength [23]. Cultivars that have relatively higher ratios of 50PI to 50PS generally have stronger dough mixing properties [23]. The chemical extraction and measurement of the amount of 50PI and 50PS gluten is a rapid and efficient method of estimating dough mixing strength rather than performing the actual dough rheological evaluation. The 50PI:50PS ratio was higher for Glenlea and AC Corrine as compared to AC Barrie and CDC Rama (Table 3).

The CWES flours produced breads that were smaller in loaf volume and had stronger crumb as measured by compression force than the CWRS flours (Table 3). Among the three CWES wheat flours, the bread loaf volume of CDC Rama was higher than that of Glenlea and AC Corrine. Compared to the other CWES cultivars, CDC Rama also had higher protein content and a lower 50PI: 50PS ratio, similar to that of the CWRS cultivar, AC Barrie (Table 3). An adequate balance of extensibility and strength is required for good breadmaking quality. Increased strength leads to higher loaf volume, but a too strong a gluten impedes the expansion of gas cells $[30,31]$ leading to lower loaf volume. The lower sedimentation volumes of CWES wheat, indicate that these flours may be overly strong and less extensible, resulting in lower loaf volumes. Similar results were reported by Khatkar et al. [32] where an extra-strong cultivar, Aubaine, showed poor baking performance in native as well as reconstituted flours. In addition to the overly long dough development times, the lower loaf volumes are another reason why extra-

Table 2. Gluten Characteristics and Effect of $10 \%$ Gluten Fortification from Composite CWRS and CWES on the Farinograph Properties of AC Meena Flour

\begin{tabular}{|c|c|c|c|c|c|c|c|c|c|}
\hline Cultivar & \multicolumn{2}{|c|}{ Gluten extract } & \multicolumn{2}{|c|}{ Wet gluten yield } & \multicolumn{5}{|c|}{ Farinograph $^{\dagger}$} \\
\hline AC Meena & & & & & $55.0^{\mathrm{f}}$ & $1.5^{\mathrm{f}}$ & $2.8^{\mathrm{g}}$ & $85.0^{\mathrm{a}}$ & $3.0^{\mathrm{e}}$ \\
\hline Composite CWRS & peak & $41.7^{\mathrm{c}}$ & $110.0^{\mathrm{a}}$ & $0.0^{\mathrm{e}}$ & $58.1^{\mathrm{e}}$ & $2.8^{\mathrm{e}}$ & $6.3^{\mathrm{e}}$ & $65.0^{\mathrm{b}}$ & $4.5^{\mathrm{d}}$ \\
\hline Composite CWRS & $50 \%$ & $30.1^{\mathrm{e}}$ & $68.5^{\mathrm{c}, \mathrm{d}}$ & $2.5^{\mathrm{b}}$ & $57.8^{\mathrm{e}}$ & $3.5^{\mathrm{c}}$ & $5.8^{\mathrm{e}, \mathrm{f}}$ & $55.0^{\mathrm{b}}$ & $5.2^{\mathrm{c}}$ \\
\hline Composite CWRS & $70 \%$ & $36.5^{\mathrm{d}}$ & $62.8^{\mathrm{e}}$ & $3.5^{\mathrm{a}}$ & $59.3^{\mathrm{d}}$ & $3.0^{\mathrm{d}}$ & $4.5^{\mathrm{e}}$ & $50.0^{\mathrm{b}}$ & $5.3^{\mathrm{c}}$ \\
\hline Composite CWES & peak & $77.7^{\mathrm{a}}$ & $87.5^{\mathrm{b}}$ & $0.6^{\mathrm{d}, \mathrm{e}}$ & $62.9^{\mathrm{b}}$ & $3.8^{\mathrm{b}}$ & $9.0^{\mathrm{d}}$ & $40.0^{c}$ & $6.5^{\mathrm{b}}$ \\
\hline Composite CWES & $30 \%$ & $78.6^{\mathrm{a}}$ & $83.2^{\mathrm{b}}$ & $0.9^{c, d}$ & $64.1^{\mathrm{a}}$ & $4.9^{\mathrm{a}}$ & $21.3^{\mathrm{a}}$ & $30.0^{c}$ & $12.2^{\mathrm{a}}$ \\
\hline
\end{tabular}

${ }^{*}$ Values in the same column with different letters are significantly different at $\mathrm{P} \leq 0.05$.

${ }^{\dagger}$ FAB: Farinograph water absorption, DDT: Dough development time, STA: Stability, MTI: Mixing tolerance index, TBD: Time to breakdown.

${ }^{\Psi}$ Mix times are based on the dough development to the peak, $30 \%$ after peak development, $50 \%$ after peak development and $70 \%$ after peak development. 
Table 3. Cultivar Characterization

\begin{tabular}{|c|c|c|c|c|c|c|c|c|c|c|c|c|}
\hline \multirow[b]{3}{*}{$\begin{array}{l}\text { Culti- } \\
\text { var }\end{array}$} & \multicolumn{4}{|c|}{ Wholemeal } & \multicolumn{8}{|c|}{ Straight-grade flour } \\
\hline & \multirow[b]{2}{*}{$\begin{array}{c}\text { Protein } \\
\text { content } \\
(\%, \\
14 \% \mathrm{mb})\end{array}$} & \multirow[b]{2}{*}{$\begin{array}{c}\text { Sedimenta- } \\
\text { tion volume } \\
(\mathrm{ml})\end{array}$} & \multirow{2}{*}{$\begin{array}{c}\text { Gluten } \\
\text { index } \\
(\%)\end{array}$} & \multirow[b]{2}{*}{$\begin{array}{l}\text { 50PI: } \\
\text { 50PS }\end{array}$} & \multicolumn{2}{|c|}{ Mixograph $^{\dagger}$} & \multicolumn{4}{|c|}{ Farinograph $^{\Psi}$} & \multicolumn{2}{|c|}{ Bread } \\
\hline & & & & & $\begin{array}{l}\text { MDT } \\
(\min )\end{array}$ & $\begin{array}{c}\text { ETP } \\
(\% \\
\text { torque/min })\end{array}$ & $\begin{array}{r}\text { FAB } \\
(\%)\end{array}$ & $\begin{array}{l}\text { DDT } \\
(\mathrm{min})\end{array}$ & $\begin{array}{l}\text { STA } \\
(\min )\end{array}$ & $\begin{array}{c}\text { TBD } \\
(\min )\end{array}$ & $\begin{array}{c}\text { Loaf } \\
\text { vol- } \\
\text { ume } \\
(\mathrm{cc})\end{array}$ & $\begin{array}{c}\text { Compres- } \\
\text { sion force } \\
\text { (g) }\end{array}$ \\
\hline $\begin{array}{c}\mathrm{AC} \\
\text { Barrie }\end{array}$ & $13.8^{\mathrm{b}}$ & $65.0^{\mathrm{a}}$ & $87.0^{\mathrm{b}}$ & $0.55^{\mathrm{c}}$ & $3.0^{\mathrm{c}}$ & $87.4^{\mathrm{b}}$ & $63.1^{\mathrm{a}}$ & $9.7^{\mathrm{c}}$ & $17.1^{\mathrm{c}}$ & $17.4^{\mathrm{c}}$ & $1030^{\mathrm{a}}$ & $130.8^{\mathrm{c}}$ \\
\hline Glenlea & $12.6^{\mathrm{c}}$ & $53.0^{\mathrm{c}}$ & $99.0^{\mathrm{a}}$ & $0.63^{\mathrm{b}}$ & $5.4^{\mathrm{b}}$ & $178.6^{\mathrm{a}}$ & $62.3^{\mathrm{a}}$ & $23.0^{\mathrm{b}}$ & $31.5^{\mathrm{b}}$ & $31.9^{\mathrm{b}}$ & $795^{\mathrm{c}}$ & $257.0^{\mathrm{a}}$ \\
\hline $\begin{array}{c}\text { AC } \\
\text { Corrine }\end{array}$ & $12.4^{\mathrm{d}}$ & $63.0^{\mathrm{b}}$ & $99.0^{\mathrm{a}}$ & $0.81^{\mathrm{a}}$ & $10.1^{\mathrm{a}}$ & $111.2^{\mathrm{b}}$ & $61.7^{\mathrm{a}}$ & $27.8^{\mathrm{a}}$ & $37.3^{\mathrm{a}}$ & $37.9^{\mathrm{a}}$ & $820^{c}$ & $248.6^{\mathrm{a}}$ \\
\hline $\begin{array}{l}\text { CDC } \\
\text { Rama }\end{array}$ & $14.2^{\mathrm{a}}$ & $52.0^{\mathrm{c}}$ & $99.0^{\mathrm{a}}$ & $0.56^{\mathrm{c}}$ & $5.4^{\mathrm{b}}$ & $173.8^{\mathrm{a}}$ & $62.6^{\mathrm{a}}$ & $26.4^{\mathrm{a}}$ & $36.0^{\mathrm{a}}$ & $36.5^{\mathrm{a}}$ & $900^{\mathrm{b}}$ & $166.7^{\mathrm{b}}$ \\
\hline
\end{tabular}

${ }^{*}$ Values in the same column with different letters are significantly different at $\mathrm{P} \leq 0.05$.

${ }^{\dagger}$ MDT: Mixograph development time, ETP: Energy to peak, FAB: Farinograph water absorption, DDT: Dough development time, STA: Stability, TBD: Time to breakdown.

${ }^{\Psi}$ FAB: Farinograph water absorption, DDT: Dough development time, STA: Stability, MTI: Mixing tolerance index, TBD: Time to breakdown.

strong wheat flours are not used for baking breads. Instead, these flours are used in blends with poor quality wheat flours to improve their overall breadmaking properties.

\section{Quality Properties of Extracted Gluten}

The physical, chemical and functional properties of gluten extracted from AC Barrie, Glenlea, AC Corrine and CDC Rama with water and with cold ethanol were compared. These glutens were extracted after mixing the dough to $30 \%$ breakdown after peak dough development. The gluten yields and protein contents of these samples are given in Table 4. The gluten yield was significantly higher with ethanol extraction than with water extraction for all cultivars. The protein content of the gluten extracts was higher with water extraction than with ethanol extraction. The wet glutens extracted by water were visually darker in appearance and had a gummy non-porous structure whereas the gluten extracts from ethanol extraction were brighter in color and had a po- rous appearance (Fig. 2), consistent with previously published work [5]. The instrumental measurement of color values $\left(\mathrm{L}^{*}, \mathrm{a}^{*}\right.$ and $\left.\mathrm{b}^{*}\right)$ of the dried and powdered gluten extracts confirmed the visual appearance. The $\mathrm{L}^{*}$ values of the water-extracted glutens were lower than those for ethanolextracted gluten extracts indicating that the ethanol extraction yielded brighter colored extracts (Table 4). The a* and $b^{*}$ color values were higher in the gluten extracted with water than those extracted with ethanol (Table 4) indicating increased redness $\left(a^{*}\right)$ and yellowness $\left(b^{*}\right)$ in these glutens. The overall darker and more colored nature of the waterextracted glutens may be due in part to their increased protein content as protein has been shown to confer darkening in wheat, flour and flour products [33].

There were significant cultivar differences within the water-extracted and within the ethanol-extracted glutens. For the water-extracted glutens, AC Barrie (CWRS) and CDC Rama (CWES) had the highest gluten yields but the lowest

Table 4. Yields, Protein Contents and Color Values of Gluten Extracts Obtained from CWRS and CWES Wheat Flours with Water and Cold Ethanol Extractions $\ddagger$

\begin{tabular}{|c|c|c|c|c|c|c|}
\hline \multirow{2}{*}{ Method of extraction } & \multirow{2}{*}{ Source of gluten extract } & \multirow{2}{*}{ Gluten yield (\%) } & \multirow{2}{*}{$\begin{array}{c}\text { Protein content } \\
(\%, 14 \% \mathrm{mb})\end{array}$} & \multicolumn{3}{|c|}{ Color } \\
\hline & & & & $\mathbf{L}^{*}$ & $a^{*}$ & $\mathbf{b}^{*}$ \\
\hline \multirow[t]{4}{*}{ Water } & AC Barrie & $24.1^{\mathrm{c}, \mathrm{d}}$ & $44.4^{\mathrm{c}}$ & $88.5^{\mathrm{c}}$ & $-0.15^{\mathrm{a}}$ & $10.12^{\mathrm{b}}$ \\
\hline & Glenlea & $14.6^{\mathrm{e}}$ & $57.7^{\mathrm{b}}$ & $87.0^{\mathrm{e}}$ & $-0.15^{\mathrm{a}}$ & $10.65^{\mathrm{a}}$ \\
\hline & AC Corrine & $17.4^{\mathrm{d}, \mathrm{e}}$ & $58.5^{\mathrm{a}}$ & $87.9^{\mathrm{d}}$ & $-0.28^{\mathrm{d}}$ & $10.55^{\mathrm{a}}$ \\
\hline & CDC Rama & $26.7^{\mathrm{b}, \mathrm{c}}$ & $39.1^{\mathrm{d}}$ & $87.1^{\mathrm{e}}$ & $-0.19^{\mathrm{b}}$ & $10.45^{\mathrm{a}}$ \\
\hline \multirow[t]{4}{*}{ Ethanol } & AC Barrie & $32.4^{\mathrm{a}, \mathrm{b}, \mathrm{c}}$ & $29.6^{\mathrm{f}}$ & $90.0^{\mathrm{b}}$ & $-0.23^{\mathrm{c}}$ & $7.25^{\mathrm{d}}$ \\
\hline & Glenlea & $31.5^{\mathrm{a}, \mathrm{b}, \mathrm{c}}$ & $31.4^{\mathrm{e}}$ & $90.8^{\mathrm{a}}$ & $-0.37^{\mathrm{e}}$ & $7.25^{\mathrm{d}}$ \\
\hline & AC Corrine & $33.5^{\mathrm{a}, \mathrm{b}}$ & $27.5^{\mathrm{h}}$ & $90.3^{\mathrm{b}}$ & $-0.40^{\mathrm{f}}$ & $7.29^{\mathrm{d}}$ \\
\hline & CDC Rama & $35.3^{\mathrm{a}}$ & $28.2^{\mathrm{g}}$ & $90.1^{\mathrm{b}}$ & $-0.35^{\mathrm{e}}$ & $7.83^{\mathrm{c}}$ \\
\hline
\end{tabular}

$\ddagger$ Values in the same column with different letters are significantly different at $\mathrm{P} \leq 0.05$. 
(a)

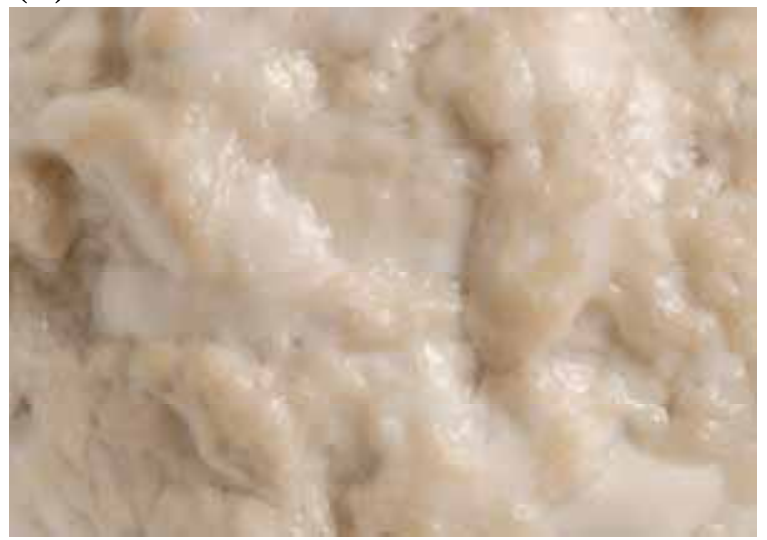

(b)

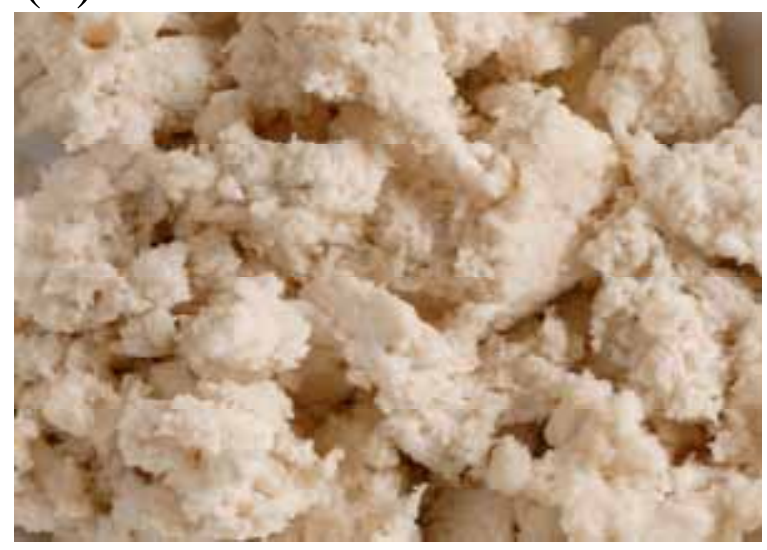

Fig. (2). Gluten extracted with (a) water and (b) cold ethanol from AC Barrie.

protein contents (Table 4). The water-extracted gluten from AC Barrie (CWRS) was brighter (L* value) and less yellow (b* value) than any of the CWES cultivars, whereas AC Barrie and Glenlea (CWES) were redder ( $\mathrm{a}^{*}$ value) in color compared to AC Corrine and CDC Rama (Table 4). There was no difference in gluten yield between cultivars for ethanol extractions although protein contents varied significantly (Table 4). For the ethanol-extracted glutens, there was very little difference in brightness ( $\mathrm{L}^{*}$ value) and yellow color $\left(\mathrm{b}^{*}\right.$ value) between cultivars (Table 4). The $\mathrm{a}^{*}$ values of $\mathrm{AC}$ Barrie (CWRS) indicated redder ethanol-extracted gluten than all other cultivars.

\section{Quality Properties of Flour/Gluten Blends}

Blends of soft wheat flour with added gluten extracts were used to evaluate gluten functionality. The farinograph analyses showed that fortification of soft wheat flour with all gluten extracts led to increased dough strength as measured by increases in stability and mixing tolerance index and an increase in time to breakdown; effects on farinograph absorption and dough development time were inconsistent (Table 5). For all four cultivars, the gluten extracts obtained by the ethanol extraction method increased the dough strength more than did the glutens extracted with water extraction method (Table 5). The flours fortified with ethanol-extracted gluten had higher dough development times, stability and time to breakdown and lower mixing tolerance index than the flours fortified with water-extracted gluten (Table 5). Additional analysis of quality indicated that the flours containing ethanol-extracted gluten were less extensible than those containing water-extracted glutens from all the four cultivars (Table 5); ethanol-extracted glutens resulted in

Table 5. Farinograph Parameters and Breadmaking Quality of the Soft Wheat Flour Fortified with Gluten Extracts to 14.5\% Protein Content ${ }^{\ddagger}$

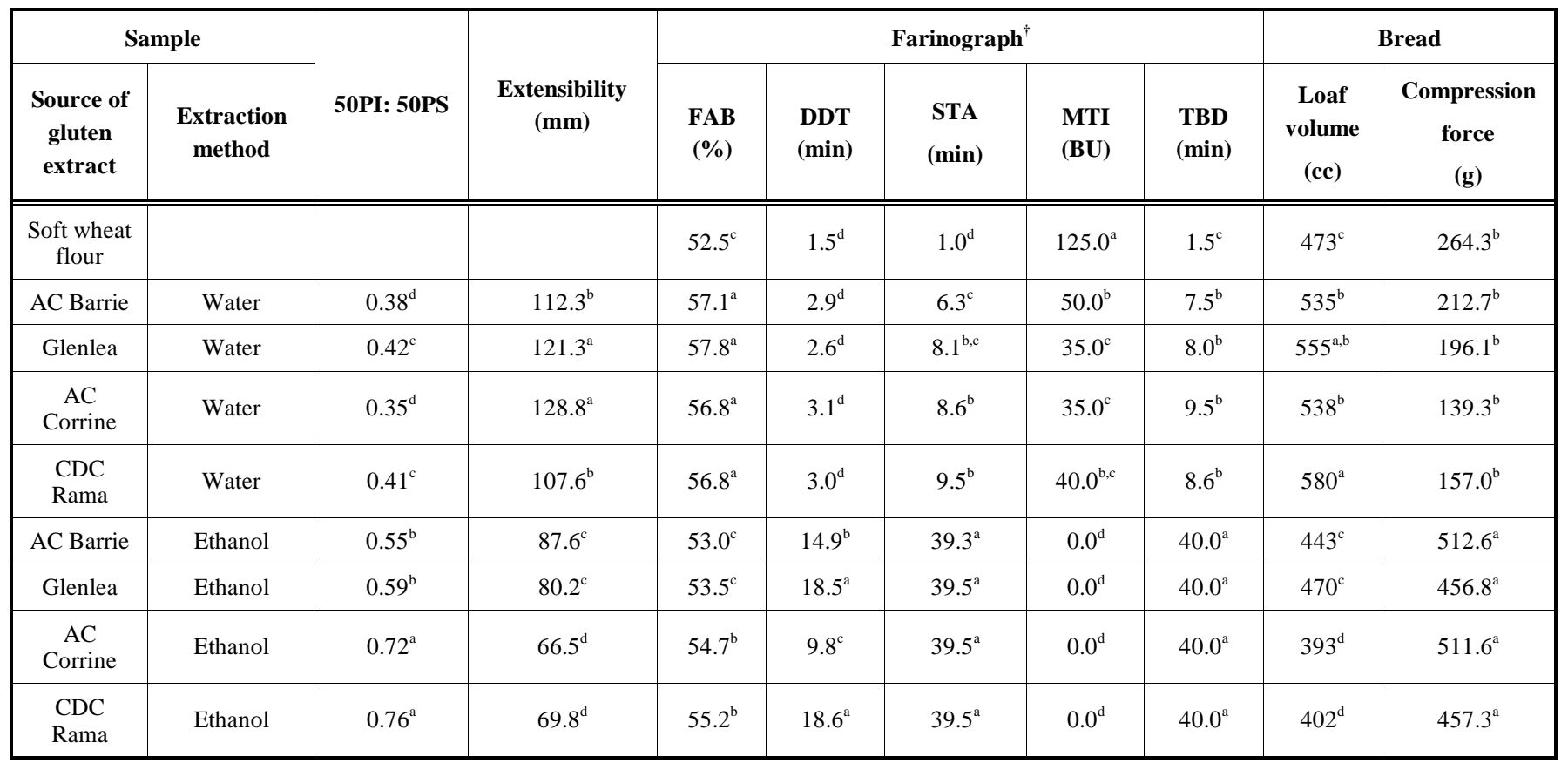

${ }^{\ddagger}$ Values in the same column with different letters are significantly different at $\mathrm{P} \leq 0.05$.

${ }^{\dagger}$ FAB: Farinograph water absorption, DDT: Dough development time, STA: Stability, MTI: Mixing tolerance index, TBD: Time to breakdown. 
a)

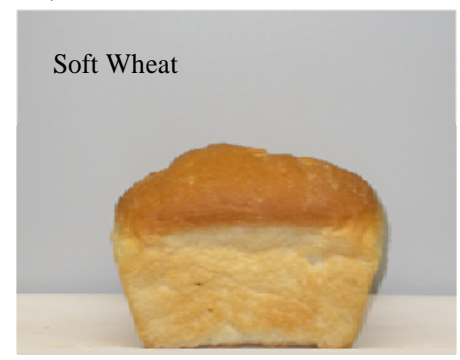

b)

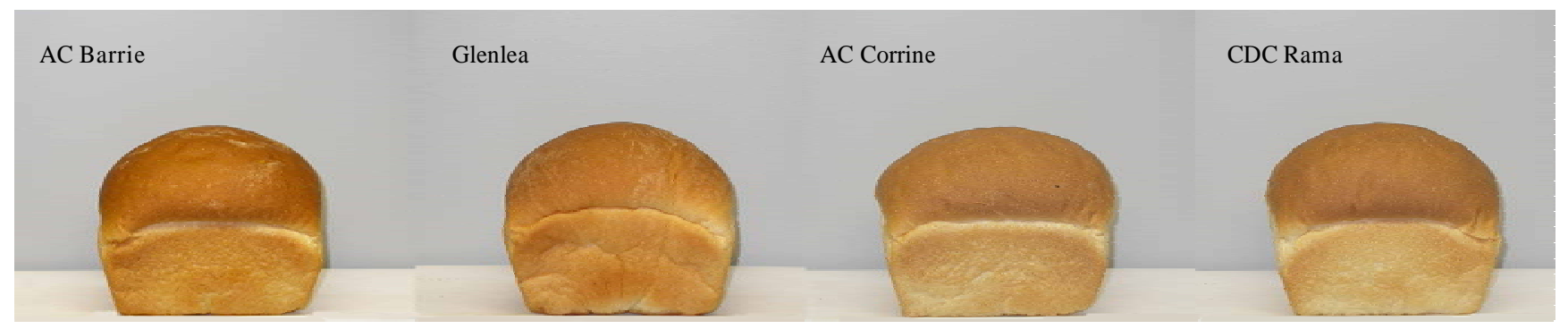

c)

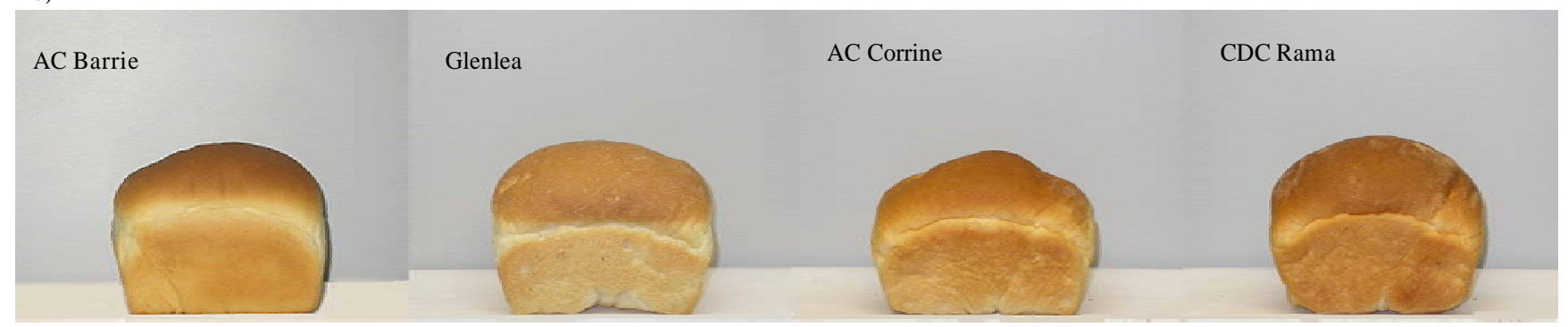

Fig. (3). Breads prepared from a) soft wheat flour, b) blends of water extracted gluten with soft wheat flour (protein, $14.5 \%$ ), and c) blends of cold ethanol extracted glutens with soft wheat flour (protein, 14.5\%).

stronger and less extensible dough. The blended flours containing gluten extracted with ethanol had higher ratios of 50PI:50PS as compared to the flours containing gluten extracted with water (Table 5). The 50PS fraction is rich in monomeric gluten components and contains both gliadins and soluble glutenins while the 50PI fraction is rich in high molecular weight glutenins [23, 34]. It is likely that ethanol extraction resulted in increased leaching of monomeric proteins compared to water extraction [8], thus reducing their content in the 50PS fraction and in the ethanol-extracted gluten. The higher proportion of 50PI in the ethanolextracted gluten/flour blends could have resulted in less extensible doughs [35].

Breads prepared from these flour-gluten breads were evaluated for loaf volume and crumb compression force (Table 5). The presence of water-extracted glutens increased the loaf volumes compared to the soft wheat flour, in contrast to flours fortified with ethanol-extracted glutens that produced loaf volumes equal to or lower than the soft wheat flour (Table 5, Fig. 3). The bread crumb strength as measured by the compression force indicated that the breads containing ethanol-extracted glutens were firmer by more than 2-fold than those containing water-extracted glutens (Table 5). This may be due to the excessively strong dough mixing characteristics of flours with ethanol-extracted glutens, which resisted the expansion of the dough during proofing and resulted in tougher and smaller loaves. The loaf volumes increased with the addition of water-extracted glutens and were correlated positively to the 50PI:50PS ratio. However, the addition of ethanol-extracted glutens to the flour further increased the 50PI:50PS ratio in the flours and disproportionately reduced extensibility, resulting in lower bread loaf volumes. Although generally higher proportions of insoluble glutenins are known to be important for the production of high bread loaf volume, excessively high amounts of insoluble glutenins may result in very strong and less extensible doughs and lower bread loaf volumes [36].

In the blends of soft wheat flour with water-extracted gluten, the extra-strong cultivars (Glenlea, AC Corrine, CDC Rama) retained some of their very strong dough properties (farinograph stability, mixing tolerance index) compared to AC Barrie (Table 5), but not to the same degree as seen in the native flour (Table 3). In contrast, the ethanol-extracted glutens and soft wheat flour blends produced extremely strong doughs (farinograph dough development time, stability, mixing tolerance index, time to breakdown) and low bread loaf volumes with very firm crumb for all cultivars; cultivars had minor effects on gluten quality when ethanol gluten extraction was used.

\section{CONCLUSIONS}

The amount of extractant and dough mixing time were optimized for the laboratory extraction of gluten. A water to flour ratio of 0.87 and dough mixing to $30 \%$ after dough 
development were most suitable for high gluten yield and quality when blended with soft wheat flour. Flours containing ethanol-extracted gluten from both CWRS and CWES cultivars, resulted in doughs with increased dough strength but lower extensibility. Thus, flours fortified with ethanolextracted glutens produced lower bread loaf volumes than flours fortified with water-extracted glutens. Flour and gluten blends with 50PI:50PS ratios of $0.41-0.42$ produced the largest loaf volumes; determination of 50PI:50PS ratios may be a useful method to measure the potential functionality of extracted gluten for baking.

The inherent flour quality characteristics of the CWES cultivars were substantially different than the CWRS cultivar AC Barrie. The extra-strong cultivars had very strong dough properties which resulted in poorer breadmaking quality than AC Barrie. The water-extracted glutens largely reflected the quality of the originating flours; dough and breadmaking quality of flours supplemented with water-extracted glutens was largely dependent on the intrinsic quality of the cultivar. There was little cultivar effect on the quality of ethanolextracted glutens; the gluten characteristics of all ethanolextracted samples were similar with strong and low extensibility doughs. The results of this study indicate that the selection of the appropriate wheat cultivar and extraction solvent are important considerations to obtaining gluten with the desired functionality.

\section{ACKNOWLEDGEMENT}

Financial support by FarmPure Inc. and the Agriculture and Agri-Food Canada Matching Investment Initiative is acknowledged. We gratefully appreciate the technical assistance of the wheat quality research team at the Cereal Research Centre. S. Dua was supported by a NSERC Visiting Fellowship to a Government Laboratory.

\section{REFERENCES}

[1] Esteller MS, Pitombo RNM, Lannes SCS. Effect of freeze-dried gluten addition on texture of hamburger buns. J Cereal Sci 2005; 41: 19-21.

[2] Gsiorowski H. Wheat wet fractionation processes. Die Nahrung 1985; 9: 879-84.

[3] Robertson GH, Cao TK. Farinograph responses for wheat flour dough fortified with wheat gluten produced by cold-ethanol or water displacement of starch. Cereal Chem 2001; 78: 538-42.

[4] Robertson GH, Cao TK. Mixograph responses of gluten and gluten-fortified flour for gluten produced by cold-ethanol or water displacement of starch from wheat flour. Cereal Chem 2002; 79: 73740.

[5] Robertson GH, Cao TK. Effect of processing on functional properties of wheat gluten prepared by cold-ethanol displacement of starch. Cereal Chem 2003; 80: 212-7.

[6] Robertson GH, Cao TK. Proteins extracted by water or aqueous ethanol during refining of developed wheat dough to vital wheat gluten and crude starch as determined by capillary-zone electrophoresis (CZE). Cereal Chem 2004; 81: 673-80.

[7] Robertson GH, Cao TK, Orts WJ. Wheat proteins extracted from flour and batter with aqueous ethanol at subambient temperatures. Cereal Chem 2007; 84: 497-501.

[8] Robertson GH, Cao TK, Orts WO. Effect on dough functional properties of partial fractionation, redistribution, and in situ deposition of wheat flour gluten proteins exposed to water, ethanol, and aqueous ethanol. Cereal Chem 2008; 85: 599-606.

[9] Georgopoulos T, Larsson H, Eliasson AC. A comparison of the rheological properties of wheat flour dough and its gluten prepared by ultracentrifugation. Food Hydrocoll 2004; 18: 143-51.

[10] Frederix SA, Courtin CM, Delcour JA. Influence of process parameters on yield and composition of gluten fractions obtained in a laboratory scale dough batter procedure. J Cereal Sci 2004; 39: 2936.

[11] Dik T, Yöndem-Makascıoğlu F, Aytac CM, Kincal NS. Wet separation of wheat flours into starch and gluten fractions: the combined effects of water to flour ratio, dough maturation time and the effects of flour aging and ascorbic acid addition. J Sci Food Agric 2002; 82: 405-13.

[12] Yöndem-Makascıoğlu F, Dik T, Aytac CM, Kincal NS. Separation of bread wheat flours into starch and gluten fractions: effect of water temperature alone or in combination with water to flour ratio. $\mathrm{J}$ Sci Food Agric 2002; 82: 414-20.

[13] Robertson GH, Cao TK, Ong I. Wheat gluten swelling and partial solubility with potential impact on starch-from-gluten separation by ethanol washing. Cereal Chem 1999; 76: 843-84.

[14] Robertson GH, Cao TK, Wood DF. Effect of morphology of mechanically developed wheat flour and water on starch from gluten separation using cold ethanol displacement. Cereal Chem 2000; 77 : 439-44.

[15] Uthayakumaran S, Lukow OM. Improving wheat for bread and tortilla production by manipulating glutenin-to-gliadin ratio. J Sci Food Agric 2005; 85: 2111-8.

[16] Dexter JE, Preston KR, Woodbeck N. Canadian wheat. In: Popper L, Schäfer W, Freund W, Eds. Future of flour a compendium of flour improvement. Dunne; Germany: Agrimedia, Bergen 2006; pp. 43-62.

[17] Hussain A, Lukow OM, McKenzie RIH. Rheological properties of gluten derived from wheat cultivars with identical HMW glutenin subunit composition. J Sci Food Agric 1998; 78: 551-8.

[18] Robertson GH, Cao T. Substitution of concentrated ethanol for water in the laboratory washing fractionation of protein and starch from hydrated wheat flour. Cereal Chem 1998; 75: 508-13.

[19] Czuchajowska Z, Paszczynska B. Is wet gluten good for baking? Cereal Chem 1996; 73: 483-9.

[20] Hayta M, Schofield JD. Heat and additive induced biochemical transitions in gluten from good and poor breadmaking quality wheats. J Cereal Sci 2004; 40: 245-56.

[21] Wadhawan CK, Bushuk W. Studies on vitality of commercial gluten. I. Physical, chemical and technological characteristics. Cereal Chem 1989; 66: 456-62.

[22] American Association of Cereal Chemists. In: Approved methods of the AACC, $10^{\text {th }}$ ed. Method 10-10, Method 38-12A, Method 4415A, Method 46-30, Method 54-12, Method 56-11. St Paul, MN: American Association of Cereal Chemists 2000.

[23] Suchy J, Lukow OM, Brown D, DePauw, R Fox S, Humphreys G. Rapid assessment of glutenin and gliadin in wheat by UV spectrophotometer. Crop Sci 2007; 47: 91-9.

[24] Voisey PW, Miller H, Kloek M. The Ottawa electronic recording dough mixer. VI. Differences between mixing bowls. Cereal Chem 1969; 46: 196-202.

[25] Ambalamaatil S, Lukow OM, Malcolmson LJ. Quality attributes of Canadian hard white spring wheat. J Food Quality 2006; 29: 15170 .

[26] Uthayakumaran S, Lukow, OM, Jordan, MC, Cloutier S. Development of genetically modified wheat to assess its dough functional properties. Mol Breeding 2003; 11: 249-58.

[27] Suchy J, Lukow OM, Ingelin ME. Dough microextensibility method using a 2-g mixograph and texture analyzer. Cereal Chem 2000; 77: 39-43.

[28] American Institute of Baking (AIB) standard texture testing procedures (white pan bread). AIB International; c2008-20011 (cited 2008 Oct 15). Available from: https://www.aibonline.org/researchandtechnical/ services/prodqualityeval/

[29] Anderson RA, Pfeifer VF, Lancaster EB, Vojnovich C, Griffin EL. Pilot-plant studies on the continuous batter process to recover gluten from wheat flour. Cereal Chem 1960; 37: 180-8.

[30] Kasarda DD. Glutenin structure in relation to wheat quality. In: Pomeranz Y, Ed. Wheat is Unique. St. Paul, MN, U.S.A: American Association of Cereal Chemists, Inc. 1989; pp. 277-302.

[31] Shewry PR, Miles MJ, Tatham AS. The prolamin storage proteins of wheat and related cereals. Prog Biophys Mol Biol 1994; 61: 37 59.

[32] Khatkar BS, Bell AE, Schofield JD. A comparative study of the inter-relationships between mixograph parameters and bread making qualities of wheat flours and glutens. J Sci Food Agric 1996; 72: 71-85. 
[33] Hatcher DW, Lukow OM, Dexter JE. Influence of environment on Canadian hard spring wheat noodle quality. Cereal Foods World 2006; 51: 184-90.

[34] Sapirstein HD, Fu BX. Intercultivar variation in the quantity of monomeric proteins, soluble and insoluble glutenin, and residue protein in wheat flour and relationships to breadmaking quality. Cereal Chem 1998; 75: 500-7.
[35] Veraverbeke WS, Delcour JA. Wheat protein composition and properties of wheat glutenin in relation to breadmaking functionality. Crit Rev Food Sci Nutr 2002; 42: 179-208.

[36] Uthayakumaran S, Gras W, Stoddard FL, Bekes F. Effect of varying protein content and glutenin-to-gliadin ratio on the functional properties of wheat dough. Cereal Chem 1999; 76: 389-94.

(c) Dua et al.; Licensee Bentham Open.

This is an open access article licensed under the terms of the Creative Commons Attribution Non-Commercial License (http://creativecommons.org/licenses/by-nc/3.0/) which permits unrestricted, non-commercial use, distribution and reproduction in any medium, provided the work is properly cited. 